for 1 year. However, if an employee files a complaint or if a fatality or catastrophe occurs within the year, OSHA may inspect your hospital. The exemption provision applies only to states under the federal OSHA program, but some states that have their own enforcement plans have adopted similar provisions. You cannot be fined under this program, and consultants do not report violations to the OSHA enforcement staff. However, OSHA requires that the hospital correct all identified hazards. Consultation visits do not guarantee that your hospital will pass a federal or state OSHA inspection. This process (discussed in OSHA pamphlet 3047) provides an opportunity to have OSHA answer your questions and to clarify their regulations.

We strongly recommend a pro-active approach. Hospital epidemiologists should seek to develop a cordial working relationship with their regional or state OSHA. By understanding the occupational health paradigm, ${ }^{9}$ finding common ground, and promoting dialogue, hospitals can decrease the unpleasantness inevitably associated with these bureaucratic incursions.

\section{REFERENCES}

1. US Department of Labor, Occupational Health and Safety Administration. Occupational exposure to bloodborne pathogens: final role. Federal Register December 6, 1991;56:6400464182.

2. Clark RA. Enforcement Policy and Procedures for O ccupational Exposure to Tuberculosis. Washington, DC: Occupational Safety and Health Administration; October 8, 1993. US Department of Labor. Memorandum to Regional Administrators.

3. Centers for Disease Control and Prevention. Guidelines for preventing the transmission of Mycobacterium tuberculosis in health-care facilities, 1994. MMWR 1994;43(No RR-13).

4. Decker MD. The OSHA bloodborne hazard standard. Infect Control H osp Epidemiol 1992;13:407-417.

5. Decker MD. OSHA enforcement policy for occupational exposure to tuberculosis. Infect Control H osp Epidemiol 1993;14:689693.

6. American Hospital Association. OSHA's Final Bloodborme Pathogens Standard: A Special Briefing. February 1992. Item 155904.

7. US Department of Health and Human Services. Biosafety in Microbiological and Biomedical Laboratories; May, 1988; publication no. NIH 888395.

8. Centers for Disease Control. Guidelines for preventing the transmission of tuberculosis in health-care settings, with special focus on HIV-related issues. MMWR 1990;(RR-17)39.

9. Gerberding JL. Occupational infectious diseases or infectious occupational diseases? Bridging the views on tuberculosis control. Infect Control Hosp Epidemiol 1993;14:686688.

\title{
HIV Transmission Reported in Dialysis Center
}

\section{by Gina Pugliese, RN, MS Medical News Editor}

The Columbian National Institute of Health and the CDC recently reported the findings of an epidemiologic investigation of a cluster of HIV infections that were associated with either a common exposure or patientto-patient transmission.

The identification of HIV antibody-positive blood specimens from three patients undergoing treatment in a dialysis center in Columbia, South America, prompted the subsequent testing of blood specimens from all dialysis center patients during the 6-year study period (19881993). A retrospective cohort study was conducted among all patients who were dialyzed in the center from January 1992 (approximately 6 months before the first seroconversion) through December 1993 (the epidemic period). Blood specimens were available from 59 of the 84 dialysis center patients during the study period. Of these, 13 (22\%) of 59 were HIV seropositive, including 10 who were HIV seroconverters (nine of whom seroconverted during the epidemic period). All HIV seroconverters had $\geqslant 10$ dialysis sessions.

The first HIV-seropositive patient dialyzed during the epidemic period (patient A) tested positive 20 days after beginning care at the dialysis center in May 1992. The risk for seroconversion among patients who received dialysis during the 4-month period when patient $\mathrm{A}$ was dialyzed was significantly higher than for those dialyzed during other months $(9 / 10$ vs $0 / 9)$. The only patient who received dialysis during the same period as patient A but who did not seroconvert had used separate patient care equipment designated for patients with hep atitis B virus infection; all other patients dialyzed during this period were recorded to have used common equipment. Risk for HIV seroconversion was not associated with any other factors.

Nucleotide HIV DNA sequence comparison indicated that the isolates obtained from four of the dialysis center converters were genetically closer to each other than to four controls.
The dialysis center had no written policies about reprocessing patient access needles, dialyzers, or blood lines. Interviews with staff nurses indicated that all dialyzers and blood lines were individually reprocessed with $5 \%$ formaldehyde and stored for reuse on same patient. However, patient access needles were reprocessed through the use of a $0.16 \%$ solution of benzalkonium chloride, involving a procedure of mixing access needles from multiple patients in a common soaking pan for disinfection. The disinfectant was changed every 7 days.

In the United States, HIV transmission in dialysis centers never has been reported. This outbreak in Columbia suggests that dialysis centers worldwide must conform to established infection-control practices.

FROM: CDC. HIV transmission in a dialysis center-Columbia, 1991 to 1993. M M WR 1995;42(21), June 2, 1995:404-405,411-412.

Velandia M, Fridkin SK, Cardenas V, et al. Transmission of HIV in dialysis centre. Lancet 1995;345:14171422 . 